\title{
REVIEW
}

\section{Investigating subdural haemorrhage in infants}

\section{A M Kemp}

\begin{abstract}
When an infant or young child presents with subdural haemorrhage, the diagnostic priority is to exclude physical child abuse. A team approach should be adopted for the clinical child protection investigation. The diagnostic process is inevitably one of detective work; appropriate radiological, ophthalmological, haematological, biochemical, and postmortem investigations are discussed.
\end{abstract}

See end of article for authors' affiliations

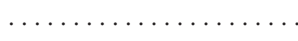

Correspondence to: Dr A M Kemp, University of Wales College of Medicine, Academic Centre, Llandough Hospital, Cardiff CF64 2XX, UK Kempam@cardiff.ac.uk

Accepted for publication 19 October 2001
$\mathrm{S}$ ubdural haemorrhage (SDH) arising from intentional injury is relatively common in infants, with an annual incidence figure of 21/100 000. ${ }^{1}$ The morbidity from shaken baby syndrome is serious: $12-30 \%$ of victims die, ${ }^{12}$ and $60-70 \%$ of the survivors suffer from significant neurological handicap. ${ }^{1-3}$

When an infant or young child has an SDH, the diagnostic priority is to exclude physical child abuse which is the commonest cause following shaking or shaking impact injury. ${ }^{1}$ Research suggests that when these children are admitted to hospital, they are often incompletely investigated. ${ }^{1}$ Information collected at this stage forms the major component of evidence for key decision making throughout the child protection process, within civil, criminal, and compensation litigation. The consequences of missing a diagnosis of physical abuse may leave children at risk of further injury, while an incorrect diagnosis of shaken baby syndrome will have profound effects on a family unit.

There are a number of features associated with $\mathrm{SDH}$ that raise the probability of abuse. ${ }^{145}$ These include retinal haemorrhages, ${ }^{1467}$ additional physical injuries, ${ }^{1489}$ and a previous history of child abuse in the family. ${ }^{14}$

As with any other clinical discipline, the field of child protection must be subject to the rigours of evidence based practice and national clinical guidelines. There are currently, however few systematic reviews in this field and a paucity of publications concerning the overall investigation of SDH. The literature ${ }^{14610}$ and child protection legislation ${ }^{11}$ support a comprehensive interagency assessment of the child and family. All young children who have a "subdural haemorrhage diagnosed on admission to hospital where there is no clear underlying medical cause or history of witnessed major accidental trauma" must have a series of essential baseline investigations. There must be a systematic interpretation process to decide whether physical child abuse has occurred or not.

Table 1 outlines the causes of SDH in infancy and early childhood. Findings must be interpreted in the context of the different causes; all have their own specific physical signs or diagnostic markers.

\section{TEAM APPROACH}

The clinical child protection investigation should be led by a paediatrician with expertise in the field. Optimal care of the sick child depends on a partnership between the clinical team and the carers, and there is often an anxiety that this will be jeopardised by invoking child protection procedures. A clinical specialist in the field can address the situation with the required level of objectivity and work with local authority child protection teams. When the child is admitted to a tertiary centre or adult centred neurosurgery unit, child protection procedures are often not initiated at a local level.

Infants suffering from SDH are commonly seen in paediatric neurology units; however, the general paediatrician will be involved with a case less frequently. The clinical expertise of the paediatric neurologist or paediatric neurosurgeon will therefore be invaluable in the discussion and management of all cases.

The Local Authority Child Protection Team must be involved early to undertake preliminary investigations ${ }^{11}$ and exclude any previous concerns of child abuse within the family unit. Early involvement of the police will identify relevant criminal records of the child's carers and ensure that any forensic investigation can be initiated as soon as possible.

\section{HISTORY AND EXAMINATION}

An SDH is usually diagnosed in an infant who presents as an acute hospital admission where child abuse is not the primary presenting complaint. The clinical presentation is variable in terms of severity, symptoms, and signs. ${ }^{1}$ There is rarely a straightforward history of events preceding the diagnosis. Frequently the carers do not identify trauma as the most likely cause of the child's symptoms and when asked for a possible cause, may propose various explanations from the days prior to admission that have little relevance.

Paediatricians are unused to conducting "forensic style" inquiries and are reminded that they can contaminate evidence by close cross examination. Open ended questions will uncover the dynamics of any traumatic events described; such as the height and forces of any alleged fall or impact, the part of the body involved, how hard the surface was, and what was the child's response after the injury. The clinician needs this

Abbreviations: $\mathrm{CT}$, computed tomography; $\mathrm{MRI}$ magnetic resonance imaging; $\mathrm{SDH}$, subdural haemorrhage 
Table 1 Recognised causes of subdural haemorrhage in infants and young children

\begin{tabular}{|c|c|}
\hline Cause of SDH & Comment \\
\hline \multicolumn{2}{|l|}{ Intentional injury } \\
\hline Shaken baby syndrome & $\begin{array}{l}\text { The commonest cause of SDH' } \\
\text { SDH is commonly associated with other } \\
\text { injuries and retinal haemorrhages. } \\
\text { However shaken baby syndrome can cause } \\
\text { isolated SDH or isolated retinal } \\
\text { haemorrhages }\end{array}$ \\
\hline \multicolumn{2}{|l|}{ Non-intentional injury ${ }^{27}$} \\
\hline \multirow[t]{2}{*}{ Major trauma, e.g road traffic accident, serious falls } & $\begin{array}{l}\text { Minor household falls rarely cause SDH. } \\
\text { SDH has been described in more serious } \\
\text { falls and in whiplash injury }\end{array}$ \\
\hline & $\begin{array}{l}\text { Retinal haemorrhages are only associated } \\
\text { with severe accidental injury }\end{array}$ \\
\hline Neurosurgical complications & $\begin{array}{l}\text { SDH commonly reported as a postoperative } \\
\text { complication of neurosurgery }\end{array}$ \\
\hline \multicolumn{2}{|l|}{ Perinatal } \\
\hline Fetal $^{28}$ & $\begin{array}{l}\text { SDH infrequently reported on fetal } \\
\text { ultrasound scans }\end{array}$ \\
\hline Traumatic labour ${ }^{29}$ & $\begin{array}{l}\text { SDH can follow traumatic delivery and be } \\
\text { associated with retinal haemorrhage }\end{array}$ \\
\hline \multicolumn{2}{|l|}{ Cranial malformations } \\
\hline Aneurysms $\mathrm{s}^{30}$ & $\begin{array}{l}\text { Spontaneous bleeding from vascular } \\
\text { malformations }\end{array}$ \\
\hline Arachnoid cysts ${ }^{31}$ & $\begin{array}{l}\text { Less serious trauma can result in SDH when } \\
\text { arachnoid cyst is present } \\
\text { Both are unlikely to be associated with } \\
\text { retinal haemorrhages unless intracranial } \\
\text { pressure is raised }\end{array}$ \\
\hline \multicolumn{2}{|l|}{ Cerebral infections } \\
\hline Meningitis $^{32} 33$ & $\begin{array}{l}\text { Postinfective subdural effusions are seen. } \\
\text { These can be associated with retinal } \\
\text { haemorrhage }\end{array}$ \\
\hline \multicolumn{2}{|l|}{ Coagulation and haematological disorders } \\
\hline $\begin{array}{l}\text { Leukaemia } \\
\text { Sickle cell anaemia }\end{array}$ & $\begin{array}{l}\text { Diagnosis will be excluded on coagulation } \\
\text { and haematological investigations. All may }\end{array}$ \\
\hline $\begin{array}{l}\text { and associated with retinal haemorrhages } \\
\text { be }\end{array}$ & be associated with retinal haemorrhages ${ }^{7}$ \\
\hline & von Willibrand's disease \\
\hline \multicolumn{2}{|l|}{$\begin{array}{l}\text { Haemorrhagic disease of the newborn }{ }^{37} \\
\text { Idiopathic thrombocytopenia purpura }{ }^{38}\end{array}$} \\
\hline \multicolumn{2}{|l|}{ Metabolic disorders } \\
\hline Glutaric aciduria ${ }^{16}$ & $\begin{array}{l}\text { Associated with widening of subdural } \\
\text { space that can result in SDH due to } \\
\text { stretching and rupture of subdural vessels }\end{array}$ \\
\hline Galactosaemia $^{39}$ & $\begin{array}{l}\text { Case reports describe associated retinal } \\
\text { haemorrhages in both conditions }{ }^{1640}\end{array}$ \\
\hline \multicolumn{2}{|l|}{ Biochemical disorder } \\
\hline Hypernatraemia ${ }^{141}$ & $\begin{array}{l}\text { SDH described in association with salt } \\
\text { poisoning, hypernatraemic dehydration }\end{array}$ \\
\hline & $\begin{array}{l}\text { Hypernatraemia may also be a } \\
\text { complication of the intracranial trauma }\end{array}$ \\
\hline
\end{tabular}

level of information to determine whether the proposed explanation is plausible. ${ }^{6}$ The number of different explanations and variation in detail from one raconteur to another must be recorded. This detail must complement a full paediatric clinical history and examination that can be overlooked during the intensive management of the sick child. Any additional signs of physical abuse should be recorded in detail, injuries measured, and clinical photographs obtained.

\section{RADIOLOGY}

Acute haemorrhage is more easily seen on cranial computed tomography (CT) than on magnetic resonance imaging (MRI). A CT scan is more readily obtained for the acutely unwell child and is more widely available. ${ }^{12}$ However, small quantities of subdural blood may be invisible on CT and it can be difficult to differentiate from fluid in the subarachnoid space. Chronic SDH may therefore look very similar to benign enlargement of the subarachnoid space which can be seen in CT scans of infants.

MRI will identify small areas of SDH and can visualise blood in positions that are not well seen on CT scan, such as the floor of the middle and posterior cranial fossae. It is also more sensitive than CT in identifying underlying parenchymal brain injury from shearing forces sustained during shaking. ${ }^{13}$ MRI can detect SDH of different ages; chronic (low attenuation) subdural collections on CT often have different signal intensities on MRI which allow differentiation in time. This is of great importance when assessing the likelihood of 
repeated abuse ${ }^{13}$; however, it does not follow that MRI enables accurate estimates of the ages of these bleeds.

All investigations requested should be accompanied by clear clinical details and relevant questions to the radiologist. The sequence of investigations that best identifies the effects of the injury and its sequelae, as well as detecting signs of any previous episode of abuse is therefore: a CT scan as the first line investigation, followed by an MRI within the first 7-10 days, repeated some 14 days later. Some tertiary centres, where there is a wider availability of MRI and expertise, are relying purely on sequential MRI as the imaging of choice. In expert hands cranial ultrasound may be incorporated as an additional diagnostic tool to monitor findings; however, paediatricians and general radiologists should not rely on cranial ultrasound as an exclusive investigation to identify or exclude an SDH.

Ideally a neuroradiologist with expertise in the field should report these investigations promptly. Many will be performed in a centre without such onsite support, when it may be necessary to ask for an opinion from the local neuroradiology centre. Some hospitals have image links to regional centres to facilitate this process.

\section{SKELETAL RADIOLOGY}

Skeletal fractures are common in these children. ${ }^{1489}$ Rib fractures are consistent with a squeezing injury, where the infant is grasped around the chest and shaken. ${ }^{9}$ Coexisting skull fractures support a shaking impact injury. ${ }^{69}$ Long bone and metaphyseal fractures ${ }^{9}$ need to be excluded. The latter are seen in association with shaking from the indirect acceleration deceleration forces to the fragile growing plate of the long bones or from forceful pulling or twisting of the limbs.

An early skeletal survey should be undertaken when the child is clinically stable and repeated at $10-14$ days. ${ }^{14}$ In practice the repeat skeletal survey is often omitted; however, follow up radiology may reveal previously unidentified fractures and enable more accurate dating of those already identified. Some centres perform an isotope bone scan in conjunction with the initial skeletal survey, ${ }^{15}$ which can identify hot spots from the early fracture healing process or subperiosteal haemorrhage. Fractures at the growing points of long bones are, however, difficult to identify on isotope bone scan.

\section{OPHTHALMOLOGY EXAMINATION}

Ophthalmological examination of the infant's eye is difficult and paediatricians often have a poor success rate. Retinal haemorrhages are characteristically at the periphery of the retina ${ }^{7}$ and are difficult to see with direct ophthalmoscopy. All children should have a retinal examination of both eyes, performed by an ophthalmologist with paediatric experience. Examination should use the indirect method after dilatation of the pupils as recommended by the working party of the Royal College of Ophthalmologists. ${ }^{7}$

\section{HAEMATOLOGY AND BIOCHEMISTRY}

These children often have a low haemoglobin on admission ${ }^{1}$ or within the first 24 hours, which may reflect the timing and extent of bleeding. A full blood count and coagulation studies will indicate blood loss, coagulation, and haematological abnormalities. Blood cultures, urea and electrolytes, and liver function tests are important to screen for infection, associated biochemical disorders, and possible intra-abdominal injury.

Screening for rarer metabolic conditions is not routinely recommended. SDH in association with glutaric aciduria is seen in cases with frontotemporal atrophy. ${ }^{16}$ If the radiological findings support this possibility, glutaric aciduria should be excluded in consultation with a paediatrician who specialises in metabolic conditions.

\section{STRATEGY MEETING}

There must be an early strategy meeting with all agencies to discuss the findings and come to a joint decision about the probability of child abuse. Social services will invoke section 47 of the Children Act $^{11}$ and initiate a child protection investigation in the majority of cases, while making provision for the immediate safety of the child and siblings.

In the cases where the cause of the SDH has not become evident and physical abuse is unlikely, consultation with tertiary specialists is recommended to exclude rarer causes.

\section{AT POSTMORTEM EXAMINATION}

Physical child abuse should be considered in any infant who dies unexpectedly. In an ideal world all such postmortem investigations should be undertaken by a paediatric pathologist in consultation with a forensic pathologist, ${ }^{17}$ and according to nationally recommended protocols. ${ }^{18}$ When SDH is diagnosed at postmortem investigation, the diagnosis needs to be approached with the same rigour and multiagency involvement. Investigations must include a full dissection of the eyes and a complete radiological skeletal survey. ${ }^{19}$ Detailed histopathology techniques can be enrolled to identify diffuse axonal injury ${ }^{20}$ and identify the degree of brain repair in order to give an idea of the timing of injury. ${ }^{10}$

\section{WHEN TO PERFORM CT}

We know that some children with SDH present with relatively mild symptoms. ${ }^{1}$ It is therefore important that paediatricians maintain a low threshold for considering this diagnosis. Many children will have a lumbar puncture as the first investigation to exclude meningitis; if this shows evidence of uniform bleeding or xanthochromia, it must be followed up with a CT scan to exclude intracerebral bleeding.

In the investigation of any child under the age of 2 years who is referred under the Child Protection Procedures, consideration should be given to performing a CT scan. This should be mandatory if the child has retinal haemorrhages, unexplained neurological findings, or an increasing head circumference, and strongly recommended in any infant with bone fractures or non-accidental bruising, or under 6 months old.

\section{QUESTIONS IN COURT}

As well as endorsing the value of good quality evidence, it is important to recognise the limitations of the evidence at various points in the process. This is never more relevant than in court, where clinicians give their opinion as expert witnesses. Questions that commonly arise concern the timing of the injury and the mechanism and forces needed to cause an SDH. The evidence to contribute to this debate is limited.

Opinion about the age of SDH is based on MRI imaging that can only suggest whether bleeds have occurred within the previous week or are older, resolving haemorrhages. ${ }^{13}$ Precise dating of associated long bone fractures is not possible, but an approximate time band can often be given according to the degree of healing evident on $x$ ray examination. ${ }^{21}$ The colour changes in retinal haemorrhages and bruises depend on the amount of bleeding into the retina or subcutaneous and surrounding tissue respectively, and a variable rate of resolution. Both have a red appearance when acute and a range of colour change when older. ${ }^{722}$ Severe retinal haemorrhages may take months to clear, milder ones resolving within weeks. ${ }^{7}$

Spectrophotometry appearance of cerebrospinal fluid after an intracranial bleed, the degree of cerebral oedema, and details of autopsy findings can contribute to the timing of injury. ${ }^{10}$ Discussion of the clinical features and the chronology of events, identified in the police and social assessment, often builds a more accurate forensic picture; however, accurate timing of the injury is rarely possible. 
Table 2 Essential baseline assessment of an infant or young child with SDH

\begin{tabular}{|c|c|}
\hline Multiagency team members & $\begin{array}{l}\text { Paediatrician with expertise in child protection } \\
\text { Paediatric neurologist and/or neurosurgeon } \\
\text { Neuroradiologist } \\
\text { Ophthalmologist } \\
\text { Area child protection team social worker and police }\end{array}$ \\
\hline Clinical history & $\begin{array}{l}\text { Full paediatric case history } \\
\text { Full documentation of all possible explanations for injury }\end{array}$ \\
\hline Social and police history & $\begin{array}{l}\text { Identify any previous child protection concerns, relevant } \\
\text { criminal record of carers }\end{array}$ \\
\hline Examination & $\begin{array}{l}\text { Thorough general examination } \\
\text { Documentation and clinical photographs of coexisting } \\
\text { injury } \\
\text { Monitor head circumference }\end{array}$ \\
\hline Ophthalmology & $\begin{array}{l}\text { Ophthalmologist to examine both eyes using indirect } \\
\text { ophthalmology through dilated pupils }\end{array}$ \\
\hline Radiology & $\begin{array}{l}\text { Initial cranial CT scan } \\
\text { Repeat neuroimaging at } 7 \text { and } 14 \text { days (MRI scan } \\
\text { preferable) } \\
\text { Discuss neuroimaging with neuroradiologist } \\
\text { Full skeletal survey: repeat imaging at } 10-14 \text { days }\end{array}$ \\
\hline Serology & $\begin{array}{l}\text { Full blood count repeated over first } 24-48 \text { hours } \\
\text { Coagulation screen } \\
\text { Urea and electrolytes, liver function tests, blood cultures }\end{array}$ \\
\hline \multicolumn{2}{|c|}{$\begin{array}{l}\text { Early strategy meeting of all agencies involved to come to a joint decision about the likely cause of SDH and } \\
\text { appropriate line of management. }\end{array}$} \\
\hline Possible outcome & Action \\
\hline Likely physical child abuse & $\begin{array}{l}\text { Social services will invoke section } 47 \text { of Children Act, } \\
\text { initiate a child protection investigation and make provision } \\
\text { for the immediate safety of the child and siblings }\end{array}$ \\
\hline Medical cause of SDH identified & $\begin{array}{l}\text { No further child protection concerns: continue medical } \\
\text { management }\end{array}$ \\
\hline $\begin{array}{l}\text { Physical child abuse unlikely, cause of SDH } \\
\text { unknown }\end{array}$ & $\begin{array}{l}\text { Further clinical investigation in consultation with tertiary } \\
\text { specialists to fully exclude all different causes of SDH }\end{array}$ \\
\hline
\end{tabular}
unknown specialists to fully exclude all different causes of SDH

Knowledge of the mechanism and the forces required to elicit SDH are based on evidence from small case studies, where perpetrators have admitted shaking the baby, ${ }^{23}$ studies of the clinical features of domestic and serious head injuries in children, ${ }^{24}{ }^{25}$ old animal based studies where monkeys have been shaken, ${ }^{26}$ and biomechanical modelling experiments. ${ }^{6}$ These studies convince us that SDH occurs after violent whiplash (acceleration-deceleration injury), but none as yet can identify the least force required for such an injury.

The clinical spectrum of these cases varies from children with multiple injuries as a result of a severe degree of violence to a child with an isolated SDH. There are accounts of babies shaken by carers with postnatal depression who cannot cope with the crying, and carers who have shaken to resuscitate an apnoeic baby. It is clear that even when the full clinical picture is evident, difficult decisions need to be made as to the intent of the assailant to harm the child.

\section{CONCLUSIONS}

The diagnostic process is one of detective work from the outset of an infant who presents with a variety of symptoms and rarely any clear history of cause. A consistent approach to the investigation, terminology, and interpretation of findings will improve the quality and accuracy of the diagnosis and management of an infant with SDH (see table 2). This must be complimented by seamless interagency cooperation with clear lines of communication.

There is evidence that clinicians are reluctant to consider a diagnosis of child abuse and often delay or fail to make an early referral to the child protection agencies. ${ }^{13}$ This can put the child and siblings at risk of further abuse, can obviate the collection of police evidence, and hinder the diagnostic process. In accordance with the Children Act 1989, ${ }^{11}$ any one who has concern that a child is suffering from significant harm should refer the matter to social services.

Research in this field is expanding and will inevitably lead to revised recommendations over time as our understanding of the condition improves.

\section{ACKNOWLEDGEMENT}

I gratefully acknowledge the funders of our research programme into SDH in infants: Childrens Research Fund, Patrick Bertould Trust, Child Safe Wales, Nuffield Foundation, and the Severnside Research Team. Dr Alicia Rawlinson, Dr Jean Price, Jane Schulte, Dr Neil Stoodley, Professor Jo Sibert, Dr Sandeep Jayawant, and Mrs Cathy Cobley are acknowledged. I would like to thank Professor Mike Green, Professor David Taylor, Dr Geoff Debelle, Dr Jane Ratcliffe, Dr Helen Carty, Dr Jane Wynn, Mr Jonathen Punt, and Dr Phil Anslow for their advice.

\section{Authors' affiliations}

A M Kemp, University of Wales College of Medicine, Academic Centre, Llandough Hospital, Cardiff CF64 2XX, UK

\section{REFERENCES}

1 Jayawant S, Rawlinson A, Gibbon F, et al. Subdural haemorrhages in infants: population based study. BM 1998;317:1558-61.

2 Haviland J, Russell RIR. Outcome after severe non accidental head injury. Arch Dis Child 1997;77:504-7.

3 Billmire ME, Myers PA. Serious head injury in infants: accident or abuse? Pediatrics 1985;75:340-2. 
4 Goldstein B, Kelly MM, Bruton D, Cox C. Inflicted versus accidental head injury in critically injured children. Crit Care Med 1993;21:1328-32.

5 Duhaime AC, Christian C, Rorke LB, Zimmerman RA. Current concepts. Nonaccidental head injury in infants - "the shaken baby syndrome". N Engl J Med 1998;338:1822-9.

6 Duhaime AC, Alario A, Lewander W J, et al. Head injury in very young children, mechanisms, injury types, and ophthalmologic findings in 100 hospitalised patients younger than two years of age. Paediatrics 1992;20:179-85.

7 The ophthalmology working party. Child abuse and the eye. Eye 1999;13:3-10.

8 Caffey J. Multiple fractures of long bones of children suffering from subdural haematoma. Am J Roentgenol 1946;56:163-7.

9 Kleinman PK. Diagnostic imaging in infant abuse. Am J Roentgenol 1990;155:703-12.

10 Brown JK, Minns RA. Non accidental head injury, with particular reference to whiplash shaking injury and medico-legal aspects. Dev Med Child Neurol 1993;35:849-69.

$11 \mathrm{DOH}$, Home Office, Department of Education and Employment, National Assembley of Wales. Working together to safegaurd children. London: DOH, 2000.

12 Roa P, Carty H, Pierce A. The acute reversal sign: comparison of medical and non-accidental injury patients. Clin Radio 1999:54:495-501.

13 Charbrol B, Decarie JC, Fortin G. Role of cranial MRI in identifying patients suffering from child abuse and presenting with unexplained neurological findings. Child Abuse Negl 1999;123:217-28.

14 Kleinman PK, Nimkin K, Spevak MR, et al. Follow up skeletal surveys in suspected child abuse. Am J Roentgenol 1996;167:893-6.

15 Jaudes PK. Comparison of radiography and radionuclide bone scanning in the detection of child abuse. Pediatrics 1984;73:166-8.

16 Morris A, Hoffman G, Naughten ER, et al. Glutaric aciduria and suspected child abuse. Arch Dis Child 1999;80:404-5.

17 Green MA. A practical approach to suspicious death in infancy-a personal view. J Clin Pathol 1998;51:561-3

18 Royal College of Pathologists. Minimum guidelines for post mortem investigation of post neonatal infant deaths and sudden deaths in infancy. Appendix 1.7.10. In: Guidelines for post mortem reports. London: Royal College of Pathologists, 1993.

19 Kleinman PK, Marks SC, Richmond JM, Blackbourne BD. Inflicted skeletal injury: a postmortem radiologic study in 31 infants. Am J Roentgenol 1995; 165:647-50.

20 Gleckman AM, Bell MD, Evans RJ, Smith TW. Diffuse axonal injury in infants with nonaccidental craniocerebral trauma: enhanced detection by beta-amyloid precursor protein immunohistochemical staining. Arch Pathol Lab Med 1999;123:146-51

21 O'Connor JF, Cohen J. Dating fractures. In: Kleinman PK, ed. Diagnostic imaging of child abuse. Baltimore: Williams \& Wilkins, 1987:103-13.
22 Stephenson T, Bialas Y. Estimation of the age of bruising. Arch Dis Child 1996;74:53-5.

23 Kleinman PK, Blackbourne BD, Marks SC, et al. Radiological contributions to the investigation and prosecution of cases of fatal child abuse. N Engl J Med 1989;320:507-11.

24 Hobbs C. Skull fracture and the diagnosis of abuse. Arch Dis Child 1984;59:246-52.

25 Williams RA. Injuries in small children resulting from witnessed and corroborated free falls. J Trauma 1991;31:1350-2.

26 Ommaya AK, Faas F, Yarnell P. Whiplash injury and brain damage: an experimental study. JAMA 1968;204:285-9.

27 Wilkins B. Head injury-abuse or accident. Arch Dis Child 1997;76:393-7.

28 Green PM, Wilson $\mathrm{H}$, Romaniuk $\mathrm{C}$, et al. Idiopathic intracranial haemorrhage in the fetus. Fetal Diagn Ther 1999;14:275-8.

29 King SJ, Boothroyd A. Cranial trauma following birth in term infants. $\mathrm{Br} J$ Radiol 1998;71:232-8.

30 Vapalahti J. A case report-intracranial arterial aneurysm in a 3 month old infant. J Neurosurg 1969;30:169-71.

31 Donaldson JW, Edwards-Brown M, Luerssen TG. Arachnoid cyst rupture with concurrent subdural hygroma. Pediatr Neurosurg 2000;32:137-9.

32 Syrogiannopoulos GA, Nelson JD, McCracken GH Jr. Subdural collections of fluid in acute bacterial meningitis: a review of 136 cases. Pediatr Infect Dis 1986:5:343-52.

33 Snedeker JD, Kaplan SL, Dodge PR, et al. Subdural effusion and its relationship with neurologic sequelae of bacterial meningitis in infancy: a prospective study. Pediatrics 1990;86:163-70.

34 Mashiyama S, Fukawa $\mathrm{O}$, Mitani S, et al. Chronic subdural hematoma associated with malignancy: report of three cases [in Japanese]. Neurol Surg 2000;28:173-8.

35 Vernant JC, Delaporte JM, Buisson G, et al. Cerebrovascular complications of sickle-cell anemia [in French]. Revue Neurologique 1988;144:465-73

36 Lutschg J, Vassella F. Neurological complications in hemophilia. Acta Paediatr Scand 1981;70:235-41.

37 Choo KE, Tan KK, Chuah SP, et al. Haemorrhagic disease in newborn and older infants: a study in hospitalized children in Kelantan, Malaysia. Ann Trop Paediatr 1994; 14:231-7.

38 Gelabert Gonzalez M, Garcia Allut A, Alvez Gonzalez F, et al. Chronic subdural hematoma in a girl with idiopathic thrombopenic purpura [in Spanish]. Anales Espanoles de Pediatria 1984;21:260-2.

39 Sychlowy A, Pyda E. Toxic diarrhea in a heterozygote with galactosemia complicated by chronic subdural hematoma [in Polish] Polski Tygodnik Lekarski 1971;26:349-51.

40 Levy $\mathrm{HL}$, Brown AE, Williams SE, de Juan E. Vitreous haemorrhage as an ophthalmic complication of galactosaemia. J Pediatr 1996;129:922-5

41 Handy TC, Hanzlick R, Shields LB, et al. Hypernatremia and subdural hematoma in the pediatric age group: is there a causal relationship? J Forensic Sci 1999;44:1114-18. 